\title{
Physicochemical properties of silver catfish (Pangasius sp.) skin collagen as influenced by acetic acid concentration
}

\author{
Hadfi, N.H. and *Sarbon, N.M. \\ School of Food Science and Technology, Universiti Malaysia Terengganu, 21030 Kuala Nerus, \\ Terengganu, Malaysia
}

\author{
Article history: \\ Received: 26 March 2019 \\ Received in revised form: 15 \\ May 2019 \\ Accepted: 16 May 2019 \\ Available Online: 22 May \\ 2019
}

\section{Keywords:}

Acid soluble collagen (ASC),

Acetic acid,

Collagen extraction,

Fish skin collagen,

Silver catfish

DOI:

https://doi.org/10.26656/fr.2017.3(6).130

\begin{abstract}
The aim of this study was to investigate the physicochemical properties of silver catfish skin collagen as affected by acetic acid concentration $(0.5 \mathrm{M}$ and $0.7 \mathrm{M})$. Acid solubilised collagen (ASC) were isolated from the skin of silver catfish (Pangasius Sp.) and were compared with commercial collagen. The yields of extracted collagen using $0.5 \mathrm{M}$ and $0.7 \mathrm{M}$ acetic acid were $10.94 \pm 0.38 \%$ and $5.47 \pm 0.20 \%$, respectively. The $\mathrm{pH}$ values for commercial collagen and extracted collagen for $0.5 \mathrm{M}$ and $0.7 \mathrm{M}$ acetic acid values were $6.52 \pm 0.04,4.04 \pm 0.06$ and $3.79 \pm 0.28$, respectively. The functional group of collagen was successfully detected, along with a flaky and fibrous morphology structure. The relative viscosity for all samples decreased with an increase in temperature. Collagen extracted with $0.5 \mathrm{M}$ acetic acid is more efficient for use as a solvent for collagen extraction since it produces a higher yield and higher fibrous collagen thickness. This study found that collagen extracted from silver catfish (Pangasius $s p$.) had the potential to be used as alternative fish collagen in various fields.
\end{abstract}

\section{Introduction}

Collagen is a fibrous protein and is the most abundant protein in animals, constituting approximately $30 \%$ of total proteins (Zhang et al., 2010). A total of 27 different types of collagen have been identified. Type I collagen is widely found in collagen connective tissue (Guillén et al., 2011). Due to its wide range of industrial applications, collagen is one of the most useful biomaterials. Its high protein content and good functional properties, including water absorption capacity, gel formation, and the ability to form and stabilize emulsions have led to strong demand for collagen in the food industry (Schmidt et al., 2016). The main sources of commercial collagen are cows and pigs. However, the supply of mammalian collagen has declined in recent years due to concerns regarding bovine and porcine health, such as the emergence of bovine spongiform encephalopathy and foot and mouth disease (Nagai et al., 2010). Therefore, a realistic alternative to mammalian collagen is fish collagen derived from skin, scales, and bone (Thuy et al., 2014).

There are three major methods for the extraction of collagen: neutral salt-soluble collagen, acid-soluble collagen (ASC), and pepsin-soluble collagen (PSC). These differ in several ways. Acid-soluble collagen (ASC) is prepared via extraction under acidic conditions, in which the collagen polypeptides are dominated by a positive charge. As a consequence, solubilization increases as repulsion among tropocollagen is enhanced (Benjakul et al., 2012). The extracting mediums used include varying concentrations of acetic acid solution, in which it is one of the factors to get better yield in collagen extracted. In addition, collagen extraction for acid-soluble collagen (ASC) is often carried out in a direct extraction method with organic acids such as acetic acid, chloroacetic acid, citric acid, or lactic acid (Skierka and Sadowska, 2007). Though inorganic acids such as hydrochloric acid have also been employed for the extraction of collagen, their efficiency is lower than organic acids (Nalinalon and Shahidi, 2012). Kiew and Don (2013), reported that the yield of extracted collagen when using $0.7 \mathrm{M}$ acetic acid is maximal and that the yield dropped quickly beyond this concentration.

The extracted collagen then must be characterized in terms of its physicochemical properties in order to determine its quality and applications. Chemical properties commonly characterized include chemical composition, amino acid composition, protein concentration, and $\mathrm{pH}$ level (Martínez-Ortiz et al., 2015; Hukmi and Sarbon, 2018; Hamdan and Sarbon, 2019). Additionally, physical properties such as molecular weight, structural properties (Kiew and Don, 2013), 
thermal properties (Bama et al., 2010), morphology analysis, solubility determination, and viscosity (Sujithra et al., 2013) have also been successfully determined. Studies have found that collagens from different tissues vary considerably in terms of chain composition, amino acid composition, and physicochemical characteristics, contributing to the specific functional requirements of each tissue (Shanmugam et al., 2012).

In the fish processing industry, a significant amount of waste $(20-80 \%$ depending upon the level of processing and type of fish) is generated. Value-added products from fish waste include proteins, oil, amino acids, minerals, enzymes, bioactive peptides, collagens and gelatins (Ghaly et al., 2013). The modern production of fish is accompanied by the accumulation of a large amount of collagen sources (bones, fins, skin, scales, viscera, etc.) that range from 30 to $70 \%$ by weight of the feedstock. The improper disposal of fish waste has adverse ecological impacts on coastal resources. Hence, the extraction of collagen from fish by-products could be a promising means to obtain value-added products and lower the scale of environmental pollution (Matmaroh et al., 2011).

Pangasius is the scientific family name for certain types of freshwater catfish primarily found in Vietnam, Cambodia, and neighbouring countries. Demand for these fish is driving an expansion of farming operations in China, Cambodia, Laos and Thailand. Related species raised in these countries include Asian catfish (Fisheries and Aquaculture Department, 2009). Silver catfish (Pangasius sp.) is the second most popular freshwater fish in Malaysia. Pangasius species have a low to moderate fat content with high levels of protein. This study was carried out to determine the effect of acetic acid concentration on the extractability and physicochemical properties of silver catfish (Pangasius $s p$.) skin collagen. The extracted collagens were also compared to commercial collagen.

\section{Materials and methods}

\subsection{Materials}

Silver catfish (Pangasius sp.) were purchased fresh from a local supplier in Kuala Terengganu and placed on ice during transportation to the laboratory. Commercial collagens from tilapia scales were purchased from the Umathy Industries Sdn. Bhd., Bandar Baru Bangi, Selangor. All reagents used in this study were of analytical grade.

\subsection{Sample preparation}

The skins of silver catfish (Pangasius sp.) were removed manually and cut into pieces after being washed meticulously with chilled distilled water. All skins were then packed in a polyethylene bag and stored at $-20^{\circ} \mathrm{C}$ until further use. All preparations were performed at $4{ }^{\circ} \mathrm{C}$ (Hukmi and Sarbon, 2018).

\subsubsection{Pre-treatment for sample}

The pre-treatment processes were conducted before the isolation of collagen. The significance of this step was to ensure that all the unwanted materials were removed and that the collagens were fully extracted without any interference. In this way, there would be no other unwanted particles to affect the yield and characteristics of collagen produced.

\subsubsection{Removal of non-collagenous proteins}

Removal of non-collagenous proteins was conducted following Hukmi and Sarbon (2018). The skins were dissolved in $0.1 \mathrm{M} \mathrm{NaOH}$ for 6 hours to remove noncollagenous proteins in the sample using sodium hydroxide $(\mathrm{NaOH})$ at a ratio of $1: 8(\mathrm{w} / \mathrm{v})$. This was followed by washing in cold distilled water until a neutral $\mathrm{pH}$ of 7 was achieved.

\subsubsection{Defatting}

The skins were defatted with 20 volumes of $10 \%$ butyl alcohol for $24 \mathrm{hrs}$ with continuously stirring. The alcohol solution was changed every eight hours. The defatted skins were washed with cold water and subject to collagen extraction by aqueous acetic acid (Kiew and Don, 2013).

\subsubsection{Isolation of acid soluble collagen (ASC)}

The acid soluble collagen (ASC) of silver catfish skin was extracted using $0.5 \mathrm{M}$ and $0.7 \mathrm{M}$ acetic acid to solution ratio of $1: 10(\mathrm{w} / \mathrm{v})$ with continuous stirring for $24 \mathrm{hrs}$. Then, the extracts were centrifuged (Gyrozen 158R, Deejan, Korea) at $10,000 \times \mathrm{g}$ for 30 mins at $4^{\circ} \mathrm{C}$ and the supernatant obtained was separated. The sample residues were re-extracted with $0.5 \mathrm{M}$ acetic acid with a sample to solution ratio of 1:10 (w/v) for $12 \mathrm{hrs}$ before recentrifugation. Both supernatants were combined and sodium chloride $(\mathrm{NaCl})$ was added to salt out until the final concentration of the supernatant was $0.7 \mathrm{M}$ for precipitation to occur. The supernatants were centrifuged again at $2,500 \times g$ to obtain the precipitate. The precipitate was then lyophilised (Huang et al., 2011). The collagen yield of ASC was calculated using the following formula:

$$
\text { Yield }(\%)=\frac{\text { Weight of dried collagen }}{\text { Weight of raw skin }} \times 100
$$


2.2.5 Chemical characteristics of silver catfish (Pangasius sp.) skin collagen

The determination of chemical characteristics of silver catfish (Pangasius sp.) skin collagen was conducted according to the AOAC method (2000). The results obtained were compared to commercial collagen.

\section{$2.2 .6 \mathrm{pH}$}

The $\mathrm{pH}$ measurement was performed according to the method by Martínez-Ortiz et al. (2015). A pH meter (Cyberscan pH 300, Eutech Instrument, Singapore) were calibrated with buffer solutions ( $\mathrm{pH} 4$ and $\mathrm{pH} 7)$. About $10 \mathrm{mg}$ of lyophilized collagen samples were homogenized via dissolution in $100 \mathrm{~mL}$ of distilled water. Then, the measurements were recorded with a glass electrode dipped into the solution (Martínez-Ortiz et al., 2015).

\subsection{Functional group of extracted collagen}

The structural properties of isolated collagen were examined using Fourier Transform Infrared Spectroscopy (FTIR) according to Rasli and Sarbon (2015), with slight modification. The infrared spectrum was set in the range from 4000 to $400 \mathrm{~cm}^{-1}$ using an infrared spectrophotometer (Nicolet, Thermo Electron, USA). The lyophilized collagens were mixed with $\mathrm{KBr}$ at a ratio of 8:10 ground in a mortar and pestle into pallets with a hydraulic press. The background spectrum without the samples was observed. Then, the $\mathrm{KBr}$ sample was placed on a plate and the sample spectrums were collected. From the peaks produced at the certain wavelength and absorbance, the functional groups (amide-A, amide II and amide III) and mode of vibration were identified.

\subsection{Morphology analysis}

For morphological analysis, the method used was that of Hamdan and Sarbon (2019) with slight modification using a scanning electron microscope. The collagen powder was mounted on an aluminium cylinder stubs ( $5 \mathrm{~mm} \times 12.5 \mathrm{~mm})$ and sputter-coated with an auto fine coater (JEOLJFC 1600, Tokyo, Japan). The microstructures of the gels were examined using a scanning electron microscope (JEOLJSM-6360LA, Tokyo, Japan) under 500X magnification.

\subsection{Viscosity}

Lyophilized collagen $(0.15 \mathrm{~g})$ was dissolved in 50 $\mathrm{mL}$ of $0.1 \mathrm{M}$ acetic acid and subjected to viscosity measurements using a viscometer (Model LVT Brookfield, USA) with spindle No.1 (100 rpm). The collagen solution was heated from 4 to $50^{\circ} \mathrm{C}$ with a heating rate of $4^{\circ} \mathrm{C} / \mathrm{min}$. Prior to viscosity determination, the solution was held for $30 \mathrm{mins}$ at each designated temperature. Measurements were carried out in triplicate. The relative viscosity was calculated in comparison to that obtained at $4{ }^{\circ} \mathrm{C}$ (Normah and Nur-Hani Suryati, 2015).

\subsection{Statistical analysis}

All experiments were performed in triplicate and data were presented as mean \pm standard deviation. A probability value of $p<0.05$ was considered significant. ANOVA analysis was performed and means comparisons were done via Tukey's test. The analysis was performed in MINITAB14.

\section{Results and discussion}

3.1 Yield of collagen extracted from the skin of silver catfish (Pangasius sp.)

The yields of collagen extracted using $0.5 \mathrm{M}$ and $0.7 \mathrm{M}$ acetic acid were $10.94 \%$ and $5.47 \%$, respectively. There was a significant difference $(p<0.05)$ in yields obtained between the two different acetic acid concentrations used for extraction (Table 1). The yield of ASC extracted by $0.5 \mathrm{M}$ acetic acid was higher than that of $0.7 \mathrm{M}$ acetic acid, perhaps due to the presence of low levels of collagen content caused by denaturation of protein during the extraction process as affected by different acid concentration (Rigo et al., 2002). In addition, the difference in the yield obtained may be due to the different solubility levels of collagen in the acidic extracting medium as affected by the different concentrations of acetic acid employed. Acetic acid has been frequently used as a solvent for collagen extraction due to its great extractability towards collagen compared to other inorganic acids such as hydrochloric acid, which results in lower efficiency and yield than organic acids (Kiew and Don, 2013). Furthermore, a very low $\mathrm{pH}$ value of the extracting medium, as in the case of $0.7 \mathrm{M}$ $(\mathrm{pH}$ 3.79), would result in a reduction of water absorption of collagen. These factors may explain the lower yield obtained by $0.7 \mathrm{M}$ acetic acid extraction.

Table 1. Yield and $\mathrm{pH}$ value of extracted collagen as compared to commercial collagen

\begin{tabular}{ccc}
\hline Samples & Yield (\%) & $\mathrm{pH}$ value \\
\hline Commercial collagen & - & $6.52 \pm 0.04^{\mathrm{a}}$ \\
Collagen with 0.5M acetic acid & $10.94 \pm 0.382^{\mathrm{a}}$ & $4.04 \pm 0.06^{\mathrm{b}}$ \\
Collagen with 0.7M acetic acid & $5.47 \pm 0.198^{\mathrm{b}}$ & $3.79 \pm 0.28^{\mathrm{b}}$ \\
\hline
\end{tabular}

The data represents (means \pm standard deviation) from three replications $n=3$. Different superscript letter $(a-b)$ shows significant difference $(\mathrm{p}<0.05)$ within column.

In comparison, the yield obtained for acid-soluble collagen (ASC) using $0.5 \mathrm{M}$ acetic acid from other findings also recorded the yield of collagen from marine 
sources as follows for the fish skin of Japanese sea bass, chub mackerel, bullhead shark and ocellate puffer fish: $51.4 \%, 49.8 \%, 50.1 \%$ and $44.7 \%$, respectively (Nagai and Suzuki, 2000; Nagai et al., 2002). The collagen yields from the bones of Japanese sea bass and horse mackerel were $40.7 \%$ and $43.5 \%$, respectively (Nagai and Suzuki, 2000). The large difference between the results obtained in this study with the study conducted previously, may due to the different species of fish in which silver catfish is the warm water fish. From the results obtained, acetic acid at $0.5 \mathrm{M}$ concentration showed the best yield for silver catfish (Pangasius sp.) skin collagen extraction. Acetic acid was used as the swelling agent because it was able to produce a higher yield of collagen with lesser loss, while offering the greatest ability to solubilize fish skin collagen (Huda et al., 2013).

\section{$3.2 \mathrm{pH}$ value}

The $\mathrm{pH}$ values obtained for collagen extracted by $0.5 \mathrm{M}$ acetic acid, $0.7 \mathrm{M}$ acetic acid and commercial collagen are presented in Table 1. There was a significant difference $(p<0.05)$ between commercial collagen and collagen extracted with varying concentrations. However, levels of extracted collagen for different concentrations were not significantly different ( $p>0.05$ ). The $\mathrm{pH}$ of the extracted collagen was affected by the concentration of acetic acid used during extraction. The commercial collagen showed a higher $\mathrm{pH}$ closer to neutral, while the extracted collagen showed a lower (acidic) pH. The various concentrations of acetic acid used in extraction affected the $\mathrm{pH}$ of collagen. This may due to the concentration of hydrogen ions in the acetic acid. A higher concentration of hydrogen ions indicates a lower $\mathrm{pH}$. Collagen extracted with $0.7 \mathrm{M}$ acetic acid has the lowest $\mathrm{pH}$ which means it has a higher concentration of hydrogen ions (Lower, 2013). The $\mathrm{pH}$ values for commercial collagen were in agreement with those from a study conducted by Martínez-Ortiz et al. (2015). Meanwhile, the low pH value obtained from the extraction of different concentration of acetic acid might be due to the low $\mathrm{pH}$ value of acetic acid used, which was 2.3 (Skierka and Sadowska, 2007). Thus, the collagen from the skin of silver catfish (Pangasius sp.) was more acidic than the commercial collagen extracted from tilapia scale and is suitable for use in the beverage and fruit juice industry.

\subsection{Functional group of extracted collagen}

Fourier Transform Infrared Spectroscopy (FTIR) results for acid soluble collagen (ASC) extracted by $0.5 \mathrm{M}$ acetic acid, $0.7 \mathrm{M}$ acetic acid and commercial collagen are shown in Table 2. Aliphatic primary amide was found in all three collagen samples. The results show that all types of collagen exhibited the same characteristic peaks for amide I $\left(1629-1650 \mathrm{~cm}^{-1}\right)$, amide II (1543-1559 $\left.\mathrm{cm}^{-1}\right)$, amide III $\left(1237-1246 \mathrm{~cm}^{-1}\right)$ and amide-A (3416-3444 $\left.\mathrm{cm}^{-1}\right)$. There were no significant differences $(p>0.05)$ for amide-A and amide III for all collagen samples. However, there was a significant difference $(p<0.05)$ for amide I between commercial and extracted collagens.

The amide-A band is associated with $\mathrm{N}-\mathrm{H}$ stretching frequency. When an $\mathrm{NH}$ group is involved with $\mathrm{H}$ bond in peptide chain of collagen, the position starts to shift to lower frequencies (Matmaroh et al., 2011). The results are in agreement with those of a study conducted by Kiew and Don (2013), who found that a free N-H stretching vibration is expected to occur in the range of $3400-3440 \mathrm{~cm}^{-1}$. According to Tylingo et al. (2016), the amide-A bands of African catfish, salmon and Baltic cod ASCs were found to be $3300,3295,3290 \mathrm{~cm}^{-1}$, respectively, which is in line with the result obtained in this study. The amide I band $\left(1600-1700 \mathrm{~cm}^{-1}\right)$ is a sensitive marker of the peptide secondary structure, mainly associated with the stretching vibrations of the carbonyl group along the polypeptide backbone (Nagai et al., 2010). Commercial collagen showed the highest wavelength for amide I compared to other samples. This may be due to the higher hydrogen bonding in the triple helical structure that would result in higher structure order of collagen and leading to an increase in the molecular order of collagen structure (Matmaroh et al., 2011).

These results are within the normal absorption range for the amide II band position (1550- $\left.1600 \mathrm{~cm}^{-1}\right)$. The peak for amide II is associated with $\mathrm{N}-\mathrm{H}$ bending and C-

Table 2. Functional group of commercial collagen and collagen extracted from skin of silver catfish (pangasius sp.) using different concentration of acetic acid

\begin{tabular}{lcccc}
\hline \multicolumn{1}{c}{ Samples } & \multicolumn{4}{c}{ Wavelength $\left(\mathrm{cm}^{-1}\right)$} \\
\cline { 2 - 5 } & amide-A & amide I & amide II & amide III \\
\hline Commercial collagen & $3416.1 \pm 20.1^{\mathrm{ab}}$ & $1650.17 \pm 3.93^{\mathrm{a}}$ & $1543.46 \pm 2.04^{\mathrm{b}}$ & $1246.05 \pm 0.70^{\mathrm{a}}$ \\
Collagen extracted with 0.5M acetic acid & $3450.8 \pm 4.3^{\mathrm{a}}$ & $1634.58 \pm 4.19^{\mathrm{b}}$ & $1545.30 \pm 0.25^{\mathrm{b}}$ & $1245.81 \pm 14.21^{\mathrm{a}}$ \\
Collagen extracted with 0.7M acetic acid & $3444.8 \pm 3.4^{\mathrm{a}}$ & $1629.42 \pm 0.08^{\mathrm{b}}$ & $1559.97 \pm 0.11^{\mathrm{a}}$ & $1237.78 \pm 0.83^{\mathrm{a}}$ \\
\hline
\end{tabular}

The data represents (means \pm standard deviation) from three replications $n=3$. Different superscript letter (a-b) shows significant difference $(p<0.05)$ within column. 
$\mathrm{N}$ stretching vibration as well as the triple helical of collagen (Wu et al., 2014). Both extracted collagens, however, showed lower values than duck feet collagen, as found by Huda et al. (2013). The shift of peaks to higher frequencies indicates an increase in the molecular order of the collagen. The amide III peak is complex with intermolecular interactions in collagen, consisting of components from $\mathrm{C}-\mathrm{N}$ stretching and $\mathrm{N}-\mathrm{H}$ in-plane bending from amide linkages, as well as absorptions arising from wagging vibrations from $\mathrm{CH}^{2}$ groups from the glycine backbone and proline sidechains (Matmaroh et al., 2011). A study conducted by Matmaroh et al. (2011) on the scale of spotted golden goatfish (Parupeneus heptacanthus) was in agreement with amide III bands for collagen extracted with $0.7 \mathrm{M}$ acetic acid which was found at wavenumber of 1237 and $1237.78 \mathrm{~cm}$ ${ }^{-1}$, respectively. In conclusion, collagen extracted with $0.5 \mathrm{M}$ and $0.7 \mathrm{M}$ acetic acid showed different wavelengths for each band in the spectra. However, these different concentrations of acetic acid had the same peaks' characteristics, which were amide I, amide III and amide $-\mathrm{A}$.

\subsection{Morphology properties}

Figures 1 (a), (b), and (c) show the morphology of ASC of silver catfish (Pangasius sp.) skin extracted with $0.5 \mathrm{M}$ acetic acid, $0.7 \mathrm{M}$ acetic acid and commercial collagen, respectively. Collagen extracted with $0.5 \mathrm{M}$ and $0.7 \mathrm{M}$ acetic acid showed a flaky structure and had different thicknesses of fibrous structure (Figure 1(a) and 1(b)). The irregular, wavy collagen fibres were found to be arranged singly or in small groups. These collagen fibrils formed bundles which varied in width and thickness. Some of them intertwined. Cross-linked fibre networks can be mediated by hydrogen bonds, hydrophobic interaction, electrostatic bonds, and entropic and dispersion forces (Kirti and Khora, 2015). The variation of width and thickness was due to the concentration of acetic acid used. Collagen extracted with $0.7 \mathrm{M}$ acetic acid had smaller width and thickness compared to collagen extracted with $0.5 \mathrm{M}$ acetic acid. The triple helix structure was affected by the concentration of hydrogen ions present in the acetic acid. The regular porous structure of collagen was clearly visible, and the collagen surface was found to be rough and uneven.

On the other hand, commercial collagen showed a flaky and wrinkled structure which was completely different from the collagen extracted by $0.5 \mathrm{M}$ and $0.7 \mathrm{M}$ acetic acid (Figure 1(c)). The wrinkled structure is due to the dehydration process during lyophilizing (Schuetz et al., 2013). According to Aminudin et al. (2015), collagen extracted from the skin of freshwater fish like
Oreochromis sp., Clarias sp., and Pangasius sp. is bounded in fibre bundles (Aminudin et al., 2015). Thus, the morphology for both $0.5 \mathrm{M}$ acetic acid and $0.7 \mathrm{M}$ acetic acid did not differ much, except for the thickness of the fibril and roughness of the collagen surface.
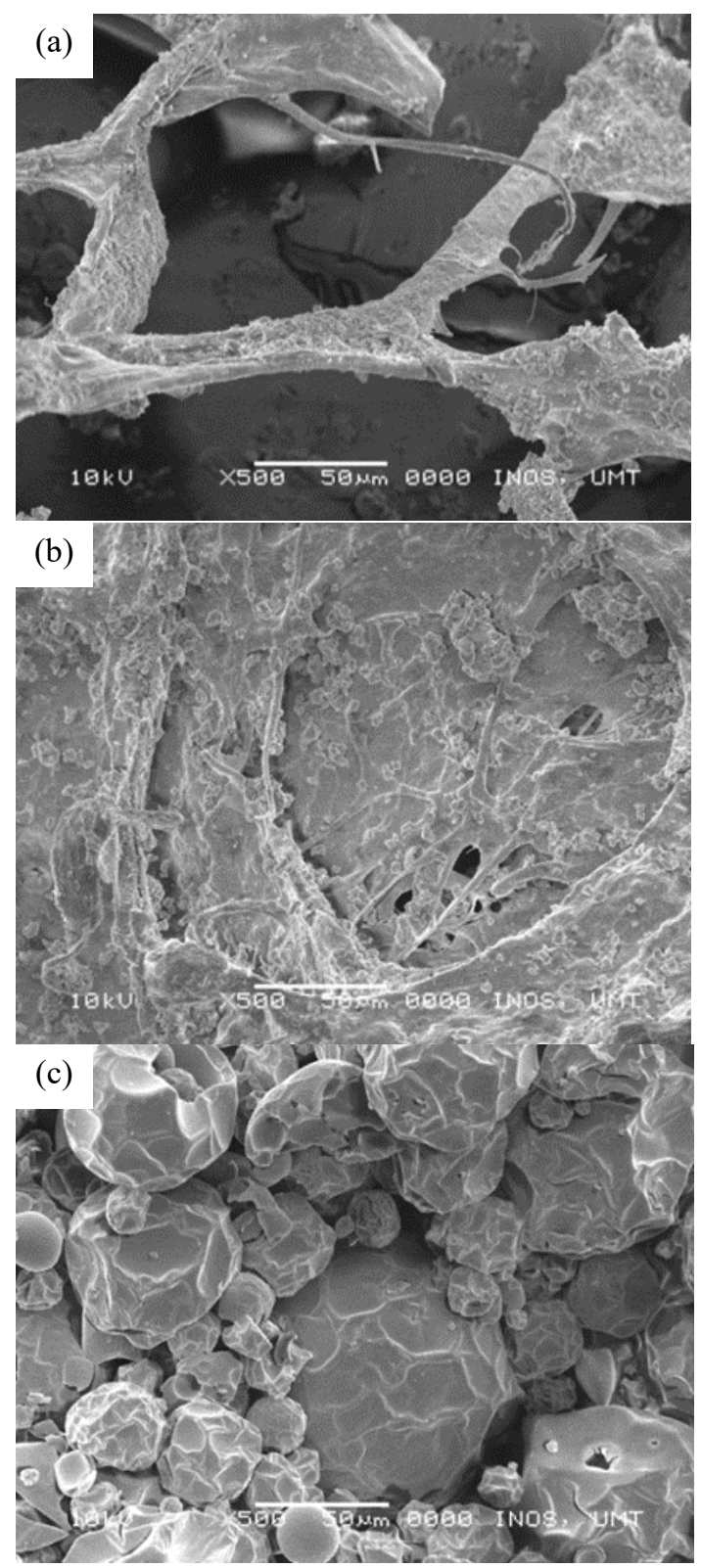

Figure 1. Microscopic structure of a) ASC from 0.5M acetic acid (b) ASC from 0.7M acetic acid (c) commercial collagen

\subsection{Viscosity of collagen}

The viscosities of commercial and extracted collagen are presented in Figure 2. The relative viscosity of commercial collagen started to decrease and then remained constant from $12^{\circ} \mathrm{C}$ until $40^{\circ} \mathrm{C}$, then suddenly increased at $44^{\circ} \mathrm{C}$, while the relative viscosity for collagen extracted by $0.7 \mathrm{M}$ acetic acid decreased continuously with an increase of heating temperature. In contrast, collagen extracted by $0.5 \mathrm{M}$ acetic acid decreased continuously from $4^{\circ} \mathrm{C}$ until $20^{\circ} \mathrm{C}$ and started to increase at $24^{\circ} \mathrm{C}, 36^{\circ} \mathrm{C}$ and $48^{\circ} \mathrm{C}$. The relative viscosity for these three samples collagen was slightly 
different, except for the commercial collagen, which showed an increase in relative viscosity when the temperature reached $44^{\circ} \mathrm{C}$.

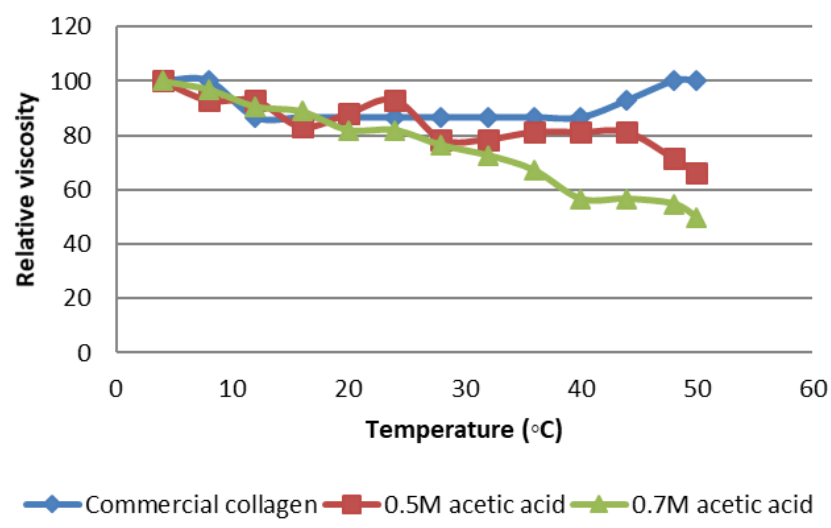

Figure 2. The relative viscosity against temperature for commercial collagen and collagen extracted from skin of silver catfish (Pangasius sp.) using different concentration of acetic acid

Relative viscosity was affected by the different acetic acid concentration used. Collagen extracted with $0.7 \mathrm{M}$ acetic acid has lower viscosity. This reduction in viscosity with an increase in temperature may be due to the increased molecular interchange, as molecules move faster in higher temperatures. The increase in temperature causes thermal energy to increase. The molecules become more mobile and viscosity is reduced (Lower, 2013). In addition, the presence of hydrogen bond in different concentration of acetic acid used also could affect the viscosity of collagen. At temperatures above $40^{\circ} \mathrm{C}$, the breakdown of hydrogen bonds and the nature of mixture random-coil single, double and triple strands cause collagen denaturing (Normah and NurHani Suryati, 2015). Once the hydrogen bonds break down, heat-treatment at high temperature may also stabilize the collagen structure (Shahiri et al., 2012). In short, the relative viscosities for these three samples of collagen decreased as the temperature increased, except for the commercial collagen, which showed an increase in relative viscosity at $44^{\circ} \mathrm{C}$.

\section{Conclusion}

Collagen from the skin of silver catfish (Pangasius $s p$.) was successfully extracted using two concentrations of acetic acid. The collagen extracted from the skin of silver catfish (Pangasius sp.) using $0.5 \mathrm{M}$ acetic acid had a higher yield than collagen extracted from the skin of silver catfish (Pangasius sp.) using $0.7 \mathrm{M}$ acetic acid. Collagen extracted with $0.5 \mathrm{M}$ acetic acid had a higher $\mathrm{pH}$ value. The functional groups observed in all collagen's samples demonstrated the presence of amideA, amide I, amide II, and amide III. Both samples were flaky and had different widths and thicknesses of fibrous structure. Meanwhile, relative viscosity for $0.5 \mathrm{M}$ extraction was higher than $0.7 \mathrm{M}$ extraction. Relative viscosity decreased as the temperature increased. Hence, collagen extracted with $0.5 \mathrm{M}$ acetic acid is more efficient for use as a solvent for collagen extraction since it produces a higher yield and higher fibrous collagen thickness. These findings suggest that silver catfish (Pangasius sp.) skin can be used as an alternative source of collagen.

\section{References}

Aminudin, A., Muhammad, S., Hamdan, R.H., Shaari, R., Nordin, M.F.M., Saufi, R.A. and Meia, S.J. (2015). Characterization of collagen extract from the skins of commercial freshwater fish. Journal Technology (Science Engineering), 77(33), 43-48. https://doi.org/10.11113/jt.v77.7003

AOAC. (2000). Official methods of analysis. Arlington, USA: Association of Official Analytical Chemists Inc.

Bama, P., Vijayalakshimi, M., Jayasimman, R., Kalaichelvan, P.T., Deccaraman, M. and Sankaranarayanan, S. (2010). Extraction of collagen from catfish (Tachysurus maculatus) by pepsin digestion and preparation and characterization of collagen chitosan sheet. International Journal of Pharmacies Science, 2(4), 133-137.

Benjakul, S., Nalinanon, S. and Shahidi, F. (2012). Fish Collagen. Food Biochemistry and Food Processing. $2^{\text {nd }}$ ed., p. 369. USA: John Wiley and Sons, Inc.

Fisheries and Aquaculture Department. (2009). Cultured Aquatic Species Information Programme Pangasius hypophthalmus (Sauvage, 1878). Food and Agriculture Organization of the United Nations. Retrieved from website: http://www.fao.org/fishery/ culturedspecies/Pangasius_hypophthalmus/en

Ghaly, A.E., Ramakrishnan, V.V., Brooks, M.S., Budge, S.M. and Dave, D. (2013). Fish processing wastes as a potential source of proteins, amino acids and oils: A Critical Review. Journal of Microbial Biochemical Technology, 5(4), 107-129.

Guillén, M.C.G., Giménez, B., Caballero, M.E.L. and Montero, M.P. (2011) Functional and bioactive properties of collagen and gelatin from alternative sources: A Review. Food Hydrocolloids, 25(8), 1813 $-1827$.

j.foodhyd.2011.02.007

https://doi.org/10.1016/

Hamdan, F.S. and Sarbon, N.M. (2019). Isolation and characterisation of collagen from fringescale sardinella (Sardinella fimbriata). International Food Research Journal, 26(1), 133 - 140.

Huda, N., Seow, E.K., Normawati, M.N. and Nik 
Aisyah, N.M. (2013). Preliminary study on physicochemical properties of duck feet collagen. International Journal of Poultry Science, 12(10), 615-621. https://doi.org/10.3923/ijps.2013.615.621

Hukmi, N.M.M. and Sarbon, N.M. (2018). Isolation and characterization of acid soluble collagen (ASC) and pepsin soluble collagen (PSC) extracted from silver catfish (Pangasius sp.) skin. International Food Research Journal, 25(5), 1785-1791.

Kiew, P.L. and Don, M.M. (2013). The Influence of Acetic Acid Concentration on the Extractability of Collagen from the Skin of Hybrid Clarias sp. and Its Physicochemical Properties: A Preliminary Study. Focusing on Modern Food Industry (FMFI), 2(3), 123-128.

Kirti and Khora, S.S. (2015). Isolation and Characterization of Collagens extracted from the Skin of Pufferfish, Lagocephalus wheeleri. Research Journal Pharmacy, Biological Chemical Science, 6 (6), 863-872.

Lower, S.K. (2013). Acid-base Equilibria and Calculations. Retrieved from Simon Fraser University website: http://www.chem1.com/acad/ webtut/aquatic/ABG-ind.html.

Martínez-Ortiz, M.A., Hernández-Fuentes, A.D., Pimentel-González, D.J., Campos-Montiel, R.G., Vargas-Torres, A. and Aguirre-Álvarez, G. (2015). Extraction and characterization of collagen from rabbit skin: partial characterization. Journal of Food, 13(2), 253-258. https:// doi.org/10.1080/19476337.2014.946451

Matmaroh, K., Benjakul, S., Prodpran, T., Encarnacion, A.B. and Kishimura, H. (2011). Characteristics of acid soluble collagen and pepsin soluble collagen from scale of spotted golden goatfish (Parupeneus heptacanthus). Food Chemistry, 129(3), 1179-1186. https:// doi.org/10.1016/j.foodchem.2011.05.099

Nagai T., Araki Y. and Suzuki N. (2002). Collagen of the skin of ocellate puffer fish (Takifugu rubripes). Food Chemistry, 78, 173-177. https:// doi.org/10.1016/S0308-8146(01)00396-X

Nagai, T. and Suzuki, N. (2000). Isolation of collagen from fish waste material, skin, bone and fins. Food Chemistry, 68(3), 277-281. https://doi.org/10.1016/ S0308-8146(99)00188-0

Nagai, T., Suzuki, N., Tanoue, Y., Kai, N. and Nagashima, T. (2010). Characterization of AcidSoluble Collagen from Skins of Surf Smelt (Hypomesus pretiosus japonicas Brevoort). Food Nutritional Science, 1, 59-66. https:// doi.org/10.4236/fns.2010.12010
Normah, I. and Nur-Hani Suryati, N.H.M.Z. (2015). Isolation of threadfin bream (Nemipterus japonicus) waste collagen using natural acid from calamansi (Citrofortunella microcarpa) juice. International Food Research Journal, 22(6), 2294-2301.

Rasli, H.I. and Sarbon, N.M. (2015). Effects of different drying methods on the rheological, functional and structural properties of chicken skin gelatin compared to bovine gelatin. International Food Research Journal, 22(2), 584-592.

Rigo, C., Hartmann, D.J. and Bairati, A. (2002). Electrophoretic and immunochemical study of collagens from Sepia officinalis cartilage. Biochemical Biophysica Acta, 1572, 77-84. https:// doi.org/10.1016/S0304-4165(02)00280-5

Schmidt, M.M., Dornelles, R.C.P., Mello, R.O., Kubota, E.H., Mazutti, M.A., Kempka, A.P. and Demiate, I.M. (2016). Collagen extraction process. International Food Research Journal, 23(3), 913922.

Schuetz, T., Richmond, N., Harmon, M.E., Schuetz, J., Castaneda, L. and Slowinska, K. (2013). The microstructure of collagen type 1 gel cross-linked with gold nanoparticles. Colloids Suft B: Biointerfaces, 101, 118-125. https://doi.org/10.1016/ j.colsurfb.2012.06.006

Shahiri, T.H., Maghsoudlou, Y., Motamedzadegan, A., Sadeghi, M.A.R. and Rostamzad, H. (2012). Study on some properties of acid-soluble collagens isolated from fish skin and bones of rainbow trout (Onchorhynchus mykiss). International Food Research Journal, 19(1), 251-257.

Shanmugam, V., Ramasamy, P., Subhapradha, N., Sudharsan, S., Seedevi, P., Moovendhan, M., Krishnamoorthy, K., Shanmugam, A. and Srinivasan, A. (2012). Extraction, structural and physical characterization of type I collagen from the outer skin of Sepiella inermis (Orbigny, 1848). African Journal Biotechnology, 11(78), 1432614337. https://doi.org/10.5897/AJB12.444

Skierka, E. and Sadowska, M. (2007). The influence of different acids and pepsin on the extractability of collagen from the skin of Baltic cod (Gadus morhua). Food Chemistry, 105(3), 1302-1306. https://doi.org/10.1016/j.foodchem.2007.04.030

Sujithra, S., Kiruthiga, N., Prabhu, M.J. and Kumeresan, R. (2013). Isolation and determination of Type I collagen from tilapia (Oreochromis niloticus) waste. International Journal of Engineering and Technology (IJET), 5(3), 0975-4024.

Thuy, L.T.M., Okazaki, E. and Osako, K. (2014). Isolation and characterization of acid-soluble 
collagen from the scales of marine fishes from Japan and Vietnam. Food Chemistry, 149, 264-270. https://doi.org/10.1016/j.foodchem.2013.10.094

Tylingo, R., Mania, S., Panek, A., Piatek, R. and Pawlowicz, R. (2016). Isolation and Characterization of Acid Soluble Collagen from the Skin of African Catfish (Clarias gariepinus), Salmon (Salmo salar) and Baltic Cod (Gadus morhua). Journal of Biotechnology Biomaterials, 6, 234. https://doi.org/10.4172/2155-952X.1000234

Wu, G.P., Wang, X.M., Lin, L.P., Chen, S.H. and Wu, Q.Q. (2014). Isolation and Characterization of Pepsin-Solubilized Collagen from the Skin of Black Carp (Mylopharyngdon piceus). Advance Bioscience Biotechnology, 5, 642650. https://doi.org/10.4236/abb.2014.57076

Zhang, M., Chen, Y., Li, G. and Du, Z. (2010). Rheological properties of fish skin collagen solution: Effects of temperature and concentration. KoreaAustralia Rheology Journal, 22(2), 119-127. 